\title{
The Effect of Quizlet on Vocabulary Acquisition
}

\author{
Abdulaziz B Sanosi \\ Prince Sattam ibn Abdulaziz University \\ Saudi Arabia \\ Email: azizsanosi [AT] gmail.com
}

\begin{abstract}
This study concerns with the major objective of foreign language teaching: vocabulary acquisition. The modern trends of teaching and the vast advance of technology enable teachers to use online and mobile applications in a very wide range. The real effect of using such a method need to be measured. Accordingly, this experimental-design study investigated the effect of Quizlet, a rapidly growing application with an online and mobile phone version, on vocabulary acquisition. Two groups of low-level EFL learners at Prince Sattam Bin Abdulaziz University in Saudi Arabia $(N=42)$ participated in the study. Each group underwent a pretest and a posttest to assess their acquisition of the assigned vocabulary lessons that were extracted from their syllabus. After using Quizlet for vocabulary learning for a month, the experimental group participants show a significant improvement in vocabulary posttest. Accordingly, the study acknowledges and recommends using the application at university level.
\end{abstract}

Keywords---- Quizlet - MALL - CALL - Vocabulary Acquisition

\section{INTRODUCTION}

There is a unanimous agreement that vocabulary is a very important aspect of second language (L2) learning. Without an adequate volume of vocabulary, it is difficult for L2 learners to communicate or even express themselves properly. Lack of knowledge of grammar or syntax, on the other hand, may distort communication, however, learners may still be understood. For these reasons, there has been a long debate about the best methods for vocabulary instructions and various suggestions concerning vocabulary acquisition were posed.

The focus of different L2 teaching methods fluctuated between grammar and vocabulary. While early approaches concentrated on grammar and internal structure of L2, subsequent trends focus on communication which requires greater mastery and larger amount of vocabulary. It is found later, however, that grammar and vocabulary are in fact interrelated and they can be considered "as partners in synergy with no discrete boundary, sometimes referred to as lexicogrammar" [1, p. 14]. This can lessen the long debate about where to focus and frees researchers and scholars to suggest methods that can account for both aspects of language simultaneously.

To enable teachers and course designers to present vocabulary effectively, researchers provide principles that can be applied in varieties of learning situations. One of the concepts suggested in this regard is learning from meaning-focused input where learners are expected to perform deliberate learning activities such as studying vocabulary from bilingual flashcards and doing cloze exercises using missing words or matching pairs [2]. Strategies of these type are now applied electronically on a wide range taking benefits of the vast advance in technology and the developing approach of Computer Assisted Language Learning (CALL). Accordingly, the effects of implementing such strategies in developing vocabulary acquisition and mastery have to be measured. The resultant findings of such measurements can give insights about adopting these trending teaching methods.

\section{LITERATURE REVIEW}

The application of CALL in language classroom has altered and expanded the field of L2 teaching and learning [3]. This change is represented in modern strategies that revolutionized teaching and learning "via scaffolding, assisting and supplementing traditional classroom learning materials and activities" [4, p. 420]. One aspect of this development is the vast use of mobile devices in classroom which have become fundamental gadgets in higher education as regarded by [5] causing new generation of CALL to emerge [4].

\subsection{Mobile Assisted Language Learning (MALL)}

By the year 2015, there were 7 billion mobile subscribers in the world [6], which represents around 96\% of the world population. This widespread of mobile phone usage makes MALL, as termed by (Chinnery) [7], an inevitable extension of CALL as the use of mobile phones dominates all aspects of life including language learning. MALL, also referred to as M-learning [8], is believed to "augment second language teaching and learning by taking it into the real world" [9, p. 71] and convert the learning process into personal, informal, interactive and ubiquitous experience [5]; [10]. Moreover, the advance in internet and the emergence of web. 2.0 technologies enhance the use of MALL. According to [11], "The 
use of the Internet has become commonplace for most mobile phone users, enabling ubiquitous access to email, music, news, e-books, e-animation, blogs, online tickets, shopping, and auctions" (p. 473) offering more effectiveness to MALL and providing remedies to learning obstacles concerning time and place [8].

New generation of MALL applications enables L2 learners to exploit web 2.0 tools to communicate and improve their linguistic skills [12]. More interactive aspects are now available to language learners including customizable eflashcards, engaging games, and collaborative activities. A famous example of these applications is Quizlet.

\subsection{Quizlet Website and Application:}

Quizlet is "a mobile and web-based study application that allows students to study information via learning tools and games" [13]. It utilizes user-designed learning modules composed of terms and their definitions or descriptions. These modules (called study sets by Quizlet) are presented to students through different learning modes including flashcards, games, collaborative activities and quizzes to allow rote learning environments that can help students master different subjects especially languages and vocabulary. The application interfaces designed for the website incorporate 8 learning modes of which 5 are available in the mobile application interface. Table 1 below compares the two different interfaces:

Table 1: Quizlet learning modes on website and mobile app

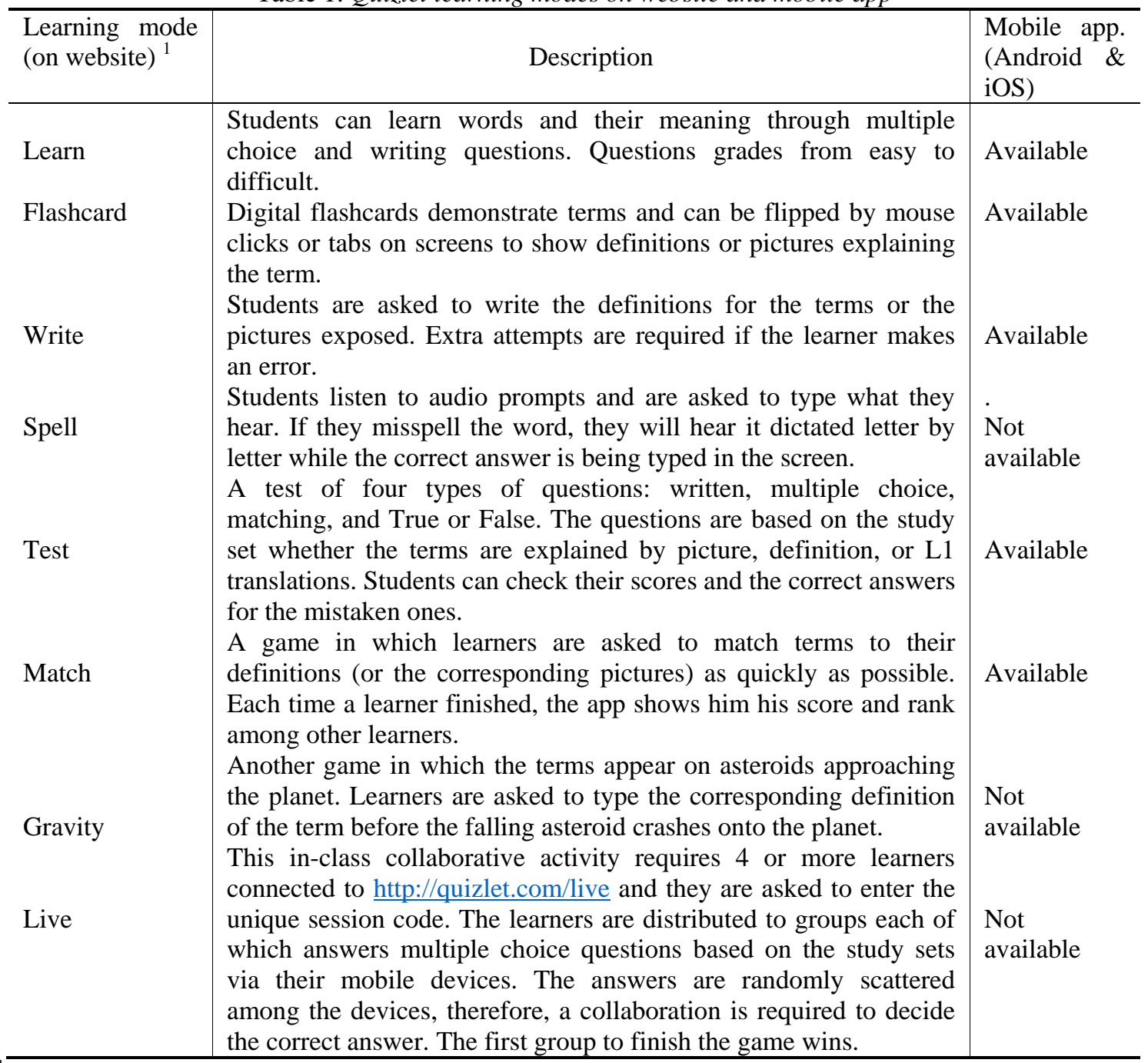

Note: ${ }^{1}$ Quizlet website address is: https://quizlet.com

All the study modes provide feedback and errors corrections that make autonomous learning highly effective. Moreover, users have more options of how to use each mode such as answering with terms or definition, playing audio or not, and studying all the terms or specific ones.

Since its public launch in 2007, learners in 130 countries have completed more than 3 billion study sessions via Quizlet website and its Android or iOS application. Around 200 million sets have been used by students in those sessions[14]. According to [15], the main advantages of Quizlet are represented in its simplicity to use and configure, its excellency for self-learning through many learning modes and the various features that are available in its free version. With exception of voice recording, diagrams and free image selection, users can use the free version to employ all the other features presented by Quizlet to design study sets for self or collaborative learning. This rapidly growing 
application has recently attracted the attention of many language researchers who explored its effect on vocabulary acquisition and students' attitudes towards its use.

\subsection{Previous Studies}

Aiming at investigating the benefits to language learners of using Quizlet to study vocabulary, (Ashcroft \& Imrie) [16] used the Substitution, Augmentation Modification, Redefinition (SAMR) Model for technology impact assessment to analyze Quizlet flashcards feature. They concluded that the application can alter students' vocabulary learning experience by the extra functionality offered by the digitalization of flashcards. The integration of those features, the researchers believe, made Quizlet a comprehensive platform for learning vocabulary.

Other researchers have investigated the actual effect of using Quizlet in and out classrooms. For example, (Andarab) [17] studied the effect of using Quizlet flashcards on EFL learners' vocabulary learning through experimental research design incorporated (52) EFL learners. The results of the study showed a significant difference between the scores of the two groups in favour of the experimental group whose members used online Quizlet flashcards for learning. Thus, Quizlet was suggested to be effective in vocabulary learning by that study. Similarly, (Dizon) [18] examined the efficacy of Quizlet in developing L2 English vocabulary by 9 university students. After examining the assigned vocabulary list for 10 weeks by using Quizlet, the posttest results showed considerable gains by the subjects compared to the pretests results. The researcher acknowledged that Quizlet can significantly enhance academic vocabulary acquisition.

Other researchers, however, were concerned with the perception of students towards Quizlet. In this regard, Kose, Cimen, and Mede [19] observed and interviewed 42 students who used Quizlet as vocabulary learning tool for four weeks. The results revealed that most of the students considered Quizlet effective especially in learning definitions, synonyms and pronunciation. Similarly, Lander [20] explored opinions of 830 low-level students about Quizlet after using it for a period of 9 months inside and outside classrooms. The results revealed that the students have shown a resounding approval of using Quizlet for learning vocabulary.

\section{METHODOLOGY}

\subsection{Purpose of the Study}

The present study follows the track of previous literature to investigate Quizlet effect on vocabulary acquisition of L2 English learners whose L1 is Arabic. To achieve this, the study tests the following hypothesis:

$H_{1}$. Quizlet improves learners' acquisition of English vocabulary.

It attempts to fill in the methodological gap that emerged in the most of the previous studies as stated below.

\subsection{Research Design}

The study employed an experimental research design incorporated a pretest-posttest control group design. Many previous studies that dealt with Quizlet adopted experimental research design that involved one group. They administer pretest and posttest to the same participant and attributed the development to the implementation of this learning technique. While it is likely to be the case, other factors may cause the progress such as practice effect [21]. The method adopted by the present study, however, is to use two groups design and to assign pretest and posttest for each of the group to minimize the potential factors that may be candidate as casual factor for any gains accomplished by the experimental group members.

\subsection{Research Sample}

Two groups of low-level male EFL learners cooperatively participated in the study. The participants were randomly divided into two groups: experimental and control group. Each group incorporated 21 students. The total 42 participants represented the vocabulary class at the College of Sciences and Humanities at Prince Sattam Bin Abdulaziz University in Saudi Arabia. According to the English language program of the college, vocabulary course is delivered in semester II which means that the students are still in their first year at university.

\subsection{Research Instrument}

Tests are the main tool used in this study. Two tests: pretest and posttest were administered to the two groups of the study. Each of the tests included 3 types of questions: multiple choice, gap-filling, and matching, and assess students' acquisition of four units of the course syllabus. The ceiling score of each test was 15 marks divided between the three questions.

\subsection{Validity and reliability}

The two tests were based on the university vocabulary syllabus (Elementary Vocabulary by B J Thomas) [22]. The pretest content was taken from the first four units which are entitled The Family, Transport, Parts of the body, and Clothes respectively. The total of the new words taught by these units are 82 words. Other four units composed the content of the posttest which are entitled Going Shopping, Work, Education and Money respectively. The total words of these units are 90 words. The manipulation of the course syllabus and the distribution of the question among the book units were meant to guarantee content validity of the test. 
Each of the two tests was administered to the female class of vocabulary at the college to pilot the research instrument. The female students' scores were utilized for calculating the Cronbach Alpha Coefficient of internal consistency by using SPSS. The reliability results are reported in table 3.6 below.

Table 2: The test reliability

\begin{tabular}{c|c|c|c}
\hline Test & Cronbach's Alpha & N of Items & $\begin{array}{l}\text { Reliability (Sqrt }{ }^{1} \text { of } \\
\text { Cronbach Alpha) }\end{array}$ \\
\hline Pretest & .808 & 15 & .89 \\
Posttest & .792 & 15 & .88 \\
\hline
\end{tabular}

The reliability of both of the tests seems convincing so the final versions of the tests were adopted to collect the research data.

\subsection{Procedures}

After the first four units of the course were taught to the students, the pretest of the study was administered to the two groups. The participants' scores were recorded for further correlation to the results of the posttest. In the second phase of the research, however, the treatment required that the experimental group members study the four assigned units using Quizlet inside and outside classroom. They attended alternative classes for four weeks where the same units were taught using Quizlet Learn, Flashcards, and Live learning modes. They were also directed to install the application on their mobile phones and study the assigned units at their homes through the other learning modes i.e. Write, Test, Match and Gravity. Meanwhile, Members of the control group continued to study the course in the regular teaching method followed since the beginning of the semester. The researcher designed a learning set for each unit where pictures, paraphrasing, and L1 annotation are used to explain the meaning of the new words figures 1 shows the study set of unit 8 (Money) and the Match learning mode of unit 5 (Going Shopping).

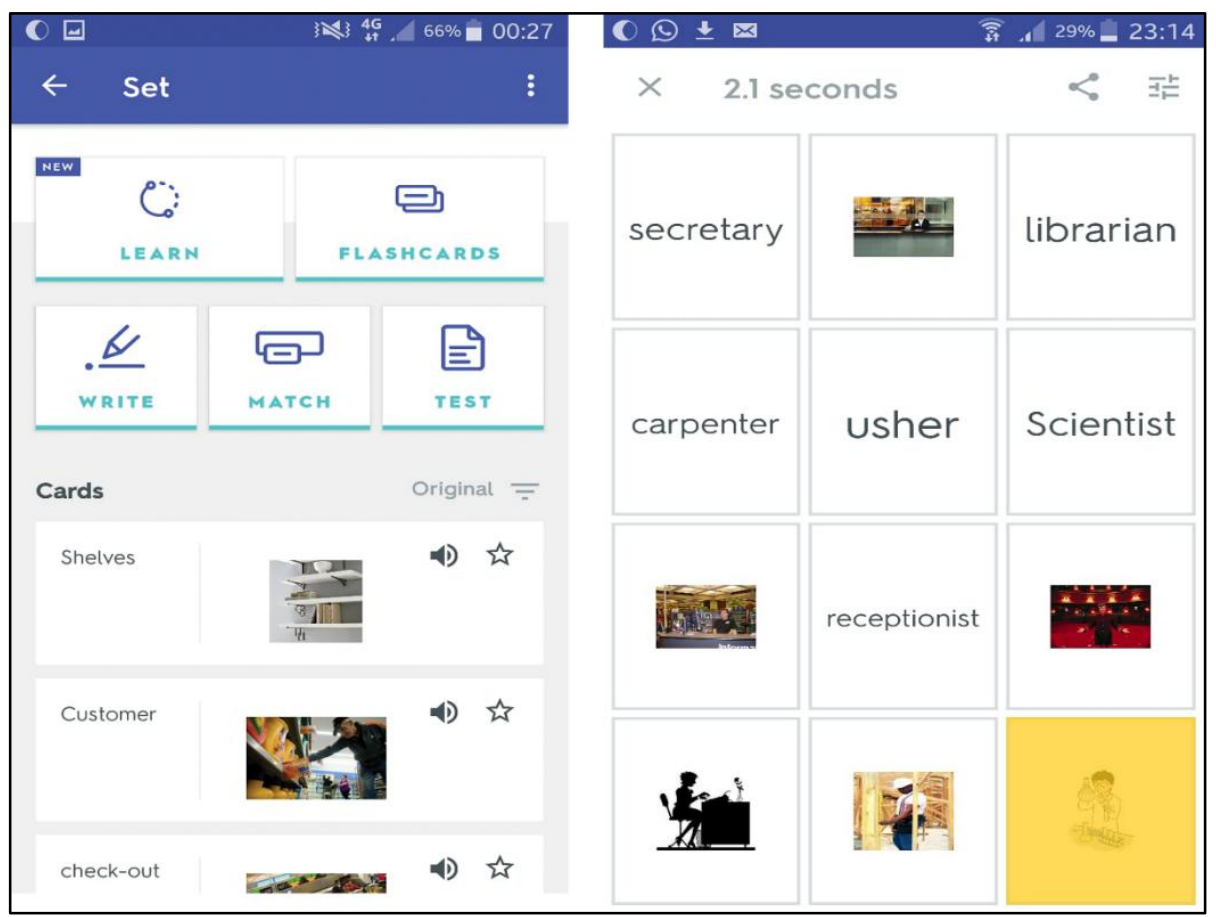

Figure 1: Study set and learning mode of two studied units as appeared in mobile device.

The Test learning mode for units 6 (Work) and the study set of unit 7 (Education) are shown in figure 2 as appeared in the website interface. 


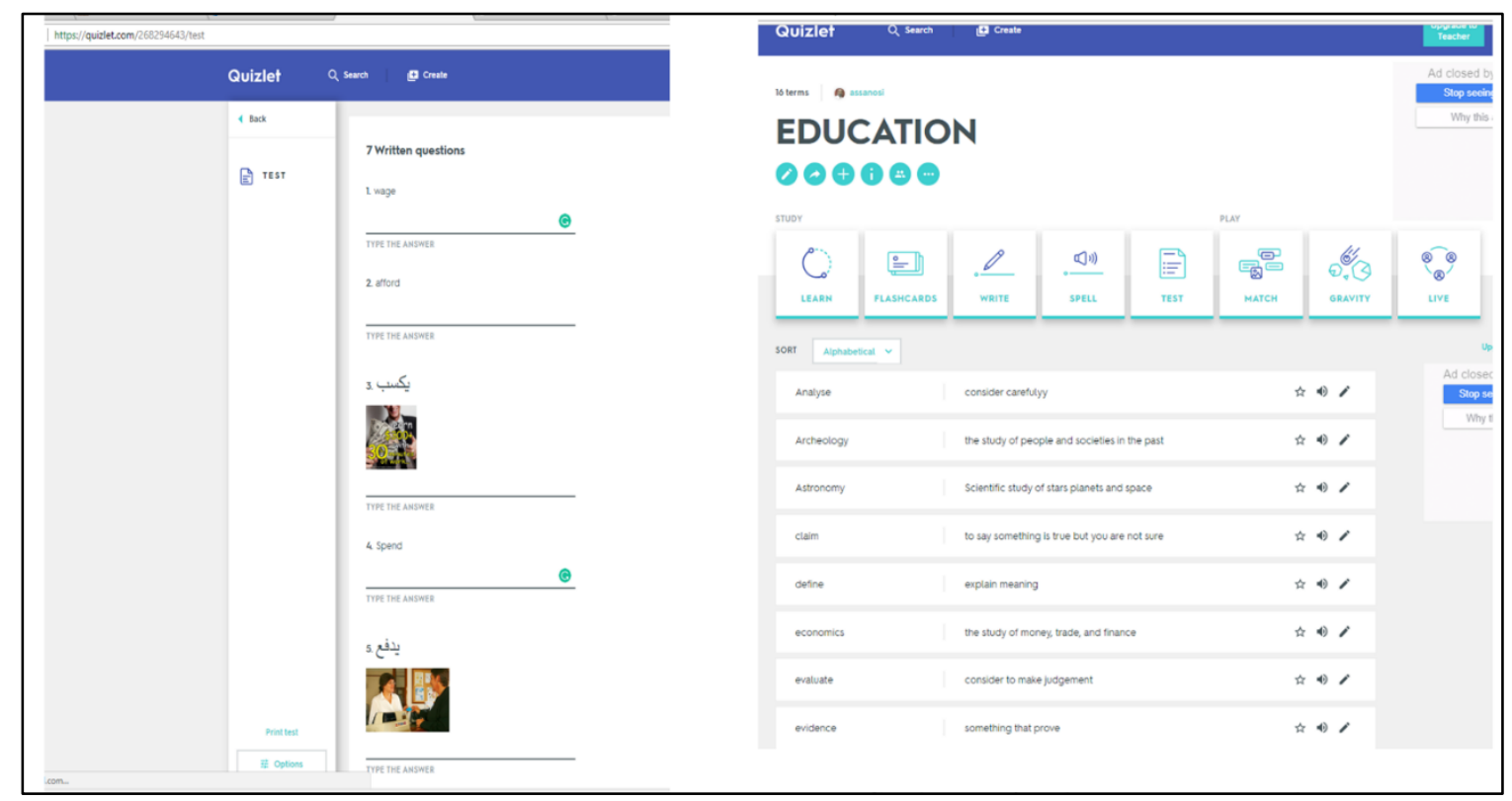

Figure 1: Study set and learning mode of two studied units as appeared in website.

The participants of the groups then underwent the posttest. The results of the two tests were then analyzed to test the research hypothesis.

\section{DATA ANALYSIS}

The participants' scores of the two tests were analysed to find out the hypothesized development that is made by members of the experimental group. For this purpose, participants' mean scores, and standard deviations (Std Dev) were computed by SPSS. To check the significance of difference between the experimental group members at pretest and posttest, a T-test was conducted. The T-value of the control group mean scores were also computed to validate the gains that might be achieved by the experimental group members.

\section{RESULTS}

Upon completing the pretest, the participants achieved the scores displayed at table 2 below.

Table 3: Mean scores and Std Dev of the participants' scores at the two tests

\begin{tabular}{c|l|l|l}
\hline Group & Test & Mean Score & Std Dev \\
\hline Control & Pretest & 6.90 & 3.72 \\
& Posttest & 7.07 & 2.43 \\
Experimental & Pretest & 6.78 & 3.49 \\
& Posttest & 10.21 & 2.65 \\
\hline
\end{tabular}

The T-test results of the scores are shown at table 3.

Table 4: T-test results of the scores

\begin{tabular}{l|c|c|c|c|c|c}
\hline \multicolumn{2}{l|}{} & Mean & N & Std Dev & t. value & p. value \\
\hline \multirow{2}{*}{ Pair 1 } & Exp_pre $^{1}$ & 6.78 & 21 & 3.49 & $-.10-$ & 0.918 \\
& Cont_pre $^{2}$ & 6.90 & 21 & 3.72 & & \\
Pair 2 & Exp_pre $^{*}$ & 6.78 & 21 & 3.49 & -3.18 & 0.005 \\
& Exp_post $^{3}$ & 10.21 & 21 & 2.65 & & 0.874 \\
Pair 3 & Cont_pre & 6.90 & 21 & 3.72 & -.16 & \\
& Cont_post & 7.07 & 21 & 2.43 & & 0.002 \\
& Exp_post & 10.21 & 21 & 2.65 & 3.51 & \\
\hline
\end{tabular}

Note. Exp_pre = experimental group pretest, Cont-pre $=$ control group pretest, Exp_post $=$ experimental group posttest, Cont_post $=$ control group posttest 


\section{DISCUSSION AND CONCLUSION}

In general, the mean scores implied that there was a clear development of the scores of the experimental group. The gains achieved by members of the group was (3.43). Given that the full mark of the test was 15, this gain could be considered prominent as it represents around $23 \%$ of the ceiling score. This result is supported further by the slight development that made by the control members although the two tests were unified. Control group members, on the other hand, have hardly shown progress with a slight difference in mean scores of 0.17 which represents only $1 \%$ of the ceiling score. Moreover, the Std Dev of the scores of the experimental group at the posttest was only 2.65 which was relatively small and suggest that their scores were more homogenous after studying with Quizlet, and hence implied that the effect of the application on all participants of this group was more consistent compared to the classic methods where a greater variation between the participants marks were witnessed.

The difference between the experimental group mean scores of the pretest and posttest was further proved significant by the T-test results. This finding is supported by the p-value of 0.005 which is below the alpha level of 0.05 . The results also showed a significant difference between the scores of the two groups in the posttest with the p-value of 0.002 . This finding suggests that the progress attained by the experimental group members is not only comparable to their pretest but also to the control group posttest. This fact minimizes the possibility of intervention of any potential factors that may cause this progress other than using Quizlet as a learning method.

The p-value of difference between control group pretest and posttest mean scores shows that the performance of the group members was almost consistent. With a 0.87 value, the difference is greater than the alpha level and thus suggests an insignificant difference between the mean scores of the two tests. Further, the homogeneity of two group members can be proved by the insignificant difference of their scores in the pretest which was of $0.91 \mathrm{p}$-value. Given all these findings into account, the effect of using Quizlet in vocabulary acquisition can safely be assumed.

As an e-learning application, the efficacy of Quizlet on improving vocabulary learning can be attributed to the augmenting role of information technology in all aspects of life. New generations of learners are accustomed to using smart devices connected to the internet to perform most of their daily tasks. Also, Quizlet represents an ideal environment for learning that can provide active learning both inside and outside classroom. Within classroom, the live learning mode provide effective collaborative experiment to students who find themselves obliged to share information and exchange answers to the vocabulary questions with a competitive spirit with other groups of students thus learning become an active cooperative process. Moreover, the study sets of Quizlet are designed to meet the need of autonomous learners. Learners can perform different learning tasks, assess their vocabulary acquisition, and gamify the vocabulary learning process. These features of Quizlet and the findings of this research and other studies imply that Quizlet can be considered a good candidate for both teachers and students for vocabulary instruction and learning.

\section{REFERENCES}

[1] N. Schmitt, Vocabulary in Language Teaching, Cambridge: Cambridge University Press, 2000.

[2] I. Nation, "Vocabulary," in Practical English Language Teaching, D. Nunan, Ed., Boston, McGraw-Hill, 2003, pp. 129-152.

[3] Z. Abdollapour and N. A. Maleki, "Second Language Vocabulary Acquisition in CALL and MALL environments and their effect on L2 vocabulary retention: A comparative study," Australian Journal of Basic and Applied Sciences, vol. 6, no. 9, pp. 109-118, 2012.

[4] A. A. I. Fageeh, "Effects of MALL applications on vocabulary acquisition and motivation," Arab World English Journal, vol. 4, no. 4, pp. 420-447, 2013.

[5] M. Kimura, H. Obari and Y. Goda, "Mobile technologies and language learning in Japan," in WorldCALL: International Perspectives on Computer-Assisted Language Learning, M. Levy, F. Blin, C. B. Siskin and O. Takeuchi, Eds., Routledge, 2011, pp. 38-54.

[6] International Telecommunication Union, "ICT facts \& figures: The world in 2015," ITU, Geneva, 2015.

[7] G. M. Chinnery, "Emerging technologies: Going to the MALL: Mobile Assisted Language Learning," Language learning \& technologies, vol. 10, no. 1, pp. 9-16, 2006.

[8] T. M. Miangah and A. Nezarat, "Mobile-Assisted Language Learning," International Journal of Distributed and Parallel Systems, vol. 3, no. 1, pp. 309-319, 2012. 
[9] A. Palalas, "Mobile-Assisted Language Learning: Designing for your students," in Second Language Teaching and Learning with Technology: Views of Emergent Researchers, S. Thouësny and L. Bradley, Eds., Dublin, 2011, pp. 71-94.

[10] I. H. Taj, N. B. Sulan, M. A. Sipra and W. Ahmad, "Impact of Mobile Assisted Language Learning (MALL) on EFL: A Meta-Analysis," Advances in language and literary studies, vol. 7, no. 2, pp. 76-83, 2016.

[11] S. Wang and N. Heffernan, "Mobile 2.0 and Mobile Language Learning," in Handbook of Research on Web 2.0 and Second Language Learning, M. Thomas, Ed., Information Science Reference, 2009, pp. 472-490.

[12] I. Cakır, "Mobile Assisted Language Learning (MALL)," in Current Trends in ELT, İ. Yaman, E. Ekmekci and M. Şenel, Eds., Ankara, NÜANS Publishing, 2016, pp. 170-189.

[13] Wikpedia, "Quizlet," 127 2018. [Online]. Available: https://en.wikipedia.org/wiki/Quizlet. [Accessed 1572018 ].

[14] "Quizlet Mission," 2018. [Online]. Available: https://quizlet.com/en-gb/mission. [Accessed 1572018$].$

[15] W. Fenton and J. Duffy, "Quizlet," 1610 2017. [Online]. Available: https://www.pcmag.com/article2/0,2817,2498480,00.asp. [Accessed 157 2018].

[16] . R. J. Ashcroft and A. C. Imrie, "Learning vocabulary with digital flashcards," in JALT2013 Conference Proceedings, Tokyo, 2014.

[17] M. S. Andarab, "The effect of using Quizlet flashcards on learning English Vocabulary," in Proceedings of 113th The IIER International Conference, Frankfurt, Germany, 2017.

[18] G. Dizon, "Quizlet in the EFL classroom: Enhancing academic vocabulary acquisition of Japanese university students," Teaching English with Technology, vol. 16, no. 2, pp. 40-56, 2016.

[19] T. Kose, E. Cimen and E. Mede, "Perceptions of EFL learners about using an online tool for vocabulary in EFL classrooms: A Pilot Project in Turkey," Procedia - Social and Behavioral Sciences, vol. 232, pp. 362-372, 2016.

[20] B. Lander, "Quizlet: what the students think - a qualitative data analysis," in CALL communities and culture - short papers from EUROCALL 2016, S. Papadima-Sophocleous, L. Bradley and S. Thouësny, Eds., 2016, pp. 254-259.

[21] Z. Dornyei, Research Methods in Applied Linguistics: Quantitative, Qualitative and Mixed Methodologies, Oxford: Oxford University Press, 2007.

[22] B. J. Thomas, Elementary Vocabulary, Edinburgh: Pearson Education, 1996. 